\title{
Taxonomia de Paspalum L., grupo Linearia (Gramineae - Paniceae) do Brasil ${ }^{1}$
}

\author{
REGINA C. OLIVEIRA ${ }^{1}$ e JOSÉ F.M. VALLS ${ }^{3}$
}

(recebido: 11 de julho de 2001; aceito: 5 de junho de 2002)

\begin{abstract}
Taxonomy of Paspalum L., Linearia group (Gramineae - Paniceae) from Brazil). A systematic treatment of the Brazilian species of Paspalum tradicionally included in the informal group Linearia is provided, including the critical analysis of each species and of their synonymy, as well as considerations on the consistency of the group and its relationships with the adjacent Notata group. An analytical key is presented to diferentiate the taxa under treatment, including very similar species of the Notata group. Detailed morphological descriptions, illustrations, geographic and ecological data, and chromosome numbers are provided. Seven species are treated in detail: Paspalum approximatum, P. crispulum, P. dedeccae, P. ellipticum, P. filifolium, $P$. lineare and $P$. pallens. Paspalum ellipticum and $P$. pallens are not considered as very typical members of the Linearia alliance.
\end{abstract}

RESUMO - (Taxonomia de Paspalum L., grupo Linearia (Gramineae - Paniceae) do Brasil). Apresenta-se um tratamento sistemático das espécies brasileiras de Paspalum L., grupo Linearia e discute-se a naturalidade do mesmo. O tratamento engloba sete espécies, $P$. approximatum, $P$. crispulum, $P$. dedeccae, $P$. ellipticum, $P$. filifolium, $P$. lineare e $P$. pallens, incluindo chave analítica para os táxons do grupo e espécies afins, descrições detalhadas, sinonímia, ilustrações, dados sobre ecologia, números cromossômicos e distribuição geográfica, além de discussões sobre a delimitação do grupo. Paspalum ellipticum e P. pallens não são considerados como membros típicos do grupo Linearia.

Key words - Gramineae, grupo Linearia, Paniceae, Paspalum, Poaceae

\section{Introdução}

O gênero Paspalum é predominantemente tropical e subtropical, com mais de 400 espécies (Quarín \& Hanna 1980). Valls \& Pozzobon (1987) estimam em 220 o número de espécies de Paspalum do Brasil.

Chase (1929), ao estudar as espécies norte-americanas de Paspalum, dividiu o gênero em 24 grupos sem nível taxonômico formal. O grupo Linearia foi constituído por uma única espécie, $P$. lineare Trin. $O$ conceito do grupo foi ampliado na monografia inédita de Chase para o gênero. Nesse trabalho inacabado, foram incluídas 10 espécies: Paspalum proximum Mez, P. ellipticum Döll, $P$. riedelii Mez, $P$. doellii Chase ined. (= P. dedeccae Quarín), P. simulans Chase, P. ovale Nees, $P$. approximatum Döll, $P$. filifolium Nees, $P$. lineare e $P$. planum Hack. Chase (dados não publicados), definiu o grupo da seguinte forma: "plantas perenes, cespitosas; colmos delgados, simples, geralmente folhosos na base; bainhas superiores

1. Parte da dissertação de mestrado de R.C. Oliveira.

2. Universidade Estadual de Campinas, Instituto de Biologia, Departamento de Botânica, Caixa Postal 6109, 13083-970 Campinas, SP, Brasil.

3. Empresa Brasileira de Pesquisa Agropecuária, Centro Nacional de Recursos Genéticos e Biotecnologia, SAIN - Parque Rural, Caixa Postal 02372, 70770-900 Brasília, DF, Brasil. alongadas, sem lâmina; lígula membranácea; "racemos" geralmente dois ou três, algumas vezes quatro ou cinco, conjugados, aproximados em $P$. ovale, ráquis delgada, flexuosa, geralmente pilosa na base; espiguetas solitárias, pareadas em $P$. ovale, e, raramente, umas poucas espiguetas pareadas em algum "racemo", em outras espécies.

Swallen (1967) descreveu quatro novas espécies brasileiras para o grupo Linearia: $P$. vescum, P. fessum, $P$. ambustum e P. crispulum.

Neste trabalho, abordam-se as espécies agrupadas em Linearia por Chase (dados não publicados) e Swallen (1967) e analisa-se sua colocação no conjunto de entidades teoricamente afins. Discutem-se, ainda, as relações entre os grupos Linearia e Notata.

\section{Material e métodos}

Exsicatas de espécies do grupo foram coletadas juntamente com mudas, incorporadas à coleção de germoplasma do Centro Nacional de Recursos Genéticos e Biotecnologia da Empresa Brasileira de Pesquisa Agropecuária e mantidas em casas de vegetação.

Analisaram-se materiais dos seguintes herbários: BAA, BHCB, BLA, BOTA, HB, CEN, CESJ, CPAP, EAC, ESAL, GUA, HRCB, IBGE, ICN, K, MBM, MO, NY, PKDC, R, RB, SI, SP, SPF, UB, UEC, US e UPCB. As siglas estão de acordo com Holmgren et al. 1990. 
Efetuaram-se cortes transversais à mão livre na porção média das lâminas foliares de materiais frescos e de herbário, as quais foram fervidas em água. Os desenhos foram feitos em câmara clara acoplada a um microscópio estereoscópico. Não se utilizaram corantes.

\section{Resultados e Discussão}

Paspalum simulans restrita ao Paraguai, não é tratada. Paspalum ovale e P. planum, talvez conspecíficas, não se ajustam a um conceito mais restrito do grupo pela presença de espiguetas pareadas e o grande número de ramos na inflorescência. Henrard (1941), acentua que $P$. epile Parodi (non P. epile Nash $1905)$ é semelhante a $P$. planum e propõe, para esta espécie, o nome P. parodianum Henrard. Paspalum parodianum parece ser sinônimo de $P$. ovale (Chase \& Niles 1962, Barreto 1974).

Paspalum ambustum é considerada sinônimo de $P$. riedelii (Renvoize 1988, Filgueiras 1993). Os fragmentos do tipo de $P$. riedelii (US) mostram espiguetas com margens pilosas, o que não concorda com a descrição de $P$. ambustum. A mesma diferenciação foi apresentada por Barreto (1974), na comparação entre $P$. ovale e $P$. riedelii, espécies aqui excluídas do grupo. É provável que $P$. ambustum seja sinônimo de $P$. ovale. A espécie paraguaia $P$. oryzoides Mez é, possivelmente, sinônimo de $P$. ovale ou de P. riedelii.

Paspalum vescum é excluída do grupo Linearia por apresentar inflorescências com apenas um ramo e pela disposição "alterniflora" das espiguetas na ráquis, enquadrando-se melhor no grupo Recta, que também se relaciona com Linearia, por suas espécies possuírem lâminas filiformes.

A inclusão de $P$. pallens no grupo Linearia por Swallen (1967) expande mais ainda os limites do grupo, tornando-o extremamente artificial, já que a espécie apresenta rizomas leptomorfos longos e estolões. Paspalum pallens foi analisada e descrita neste trabalho, por ser uma espécie pouco conhecida, mas não se relaciona com as demais espécies de Linearia.

O grupo Linearia é um agrupamento complexo e morfologicamente heterogêneo. Quando retiradas as espécies discrepantes, como $P$. pallens e as que podem ser separadas nos grupos Recta e no complexo de formas incluídas em $P$. ovale, Linearia torna-se um grupo mais homogêneo e intimamente relacionado a Notata. Uma vez que Notata e Linearia não mostram limites bem definidos, seria até possível agrupá-los. Para o presente tratamento, porém, aprofunda-se o estudo das espécies que melhor comporiam Linearia, já que as do grupo Notata, em sua quase totalidade, foram recentemente revisadas por Canto-Dorow et al. (1996). A seguir, discute-se a pertinência dos diferentes caracteres morfológicos utilizados para a distinção dos grupos Linearia e Notata.

Chase (1929) separou $P$. lineare do grupo Notata pelo formato das espiguetas, elípticas a levemente ovadas em $P$. lineare e suborbiculares, fortemente ovadas ou obovadas nas espécies de Notata. Contudo, Chase (dados não publicados), incluiu P. cromyorrhizon e $P$. ionanthum no grupo Notata, tornando tal caráter sem valor distintivo, já que estas espécies possuem espiguetas elípticas. Valls \& Pozzobon (1987) também alertaram para a similaridade morfológica de P. maculosum Trin., P. ionanthum Chase, P. cromyorrhizon Trin. ex Döll, P. ellipticum e $P$. proximum, que situaram no grupo Notata, com espécies do grupo Linearia. Barreto (1974), porém, questionou a posição de $P$. ellipticum no grupo Notata, incluindo-a em um grupo à parte, Elliptica.

A forma da lâmina poderia ser um caráter de distinção entre Linearia e Notata. Folhas planas seriam característica das espécies de Notata e filiformes das de Linearia. No entanto, os limites dos dois grupos se sobrepõem quanto à forma da lâmina foliar, no que tange a espécies extremas de Notata ( $P$. cromyorrhizon e $P$. ionanthum) e de Linearia ( $P$. dedeccae). Fenológica e ecologicamente, estas espécies são muito próximas. O gradiente morfológico se inicia em $P$. cromyorrhizon (figura 1C, D), que possui lâminas planas até filiformes. A lâmina foliar de P. ionanthum (figura $1 \mathrm{I}, \mathrm{J}$ ) vai desde totalmente subconvoluta a estreitada no terço inferior ("pseudo-pecíolo") e levemente plana na porção apical, até totalmente plana no terço superior, com o "pseudo-pecíolo" de curto a longo. Quando o "pseudo-pecíolo" é mais longo, as lâminas são iguais às de $P$. dedeccae (figura $1 \mathrm{G}, \mathrm{H}$ ). Por outro lado, o tecido parenquimático no centro das lâminas foliares revela forte relação entre $P$. dedeccae e $P$. lineare (figura $1 \mathrm{H}, \mathrm{S}$ ).

A ocorrência de hilo elíptico nas espécies brasileiras de Paspalum grupo Linearia é mais um fator de aproximação com $P$. ionanthum e $P$. cromyorrhizon, do grupo Notata (figura 2).

Seis tipos de hilo são reconhecidos para gramíneas: elíptico, lanceolado, linear, punctiforme, punctiforme-circular e reniforme (Kinges 1961, Filgueiras 1986). Dificilmente ocorrem formas intermediárias (Sendulsky et al. 1986). O hilo punctiforme é predominante entre as espécies da subfamília Panicoideae. Entretanto, os 


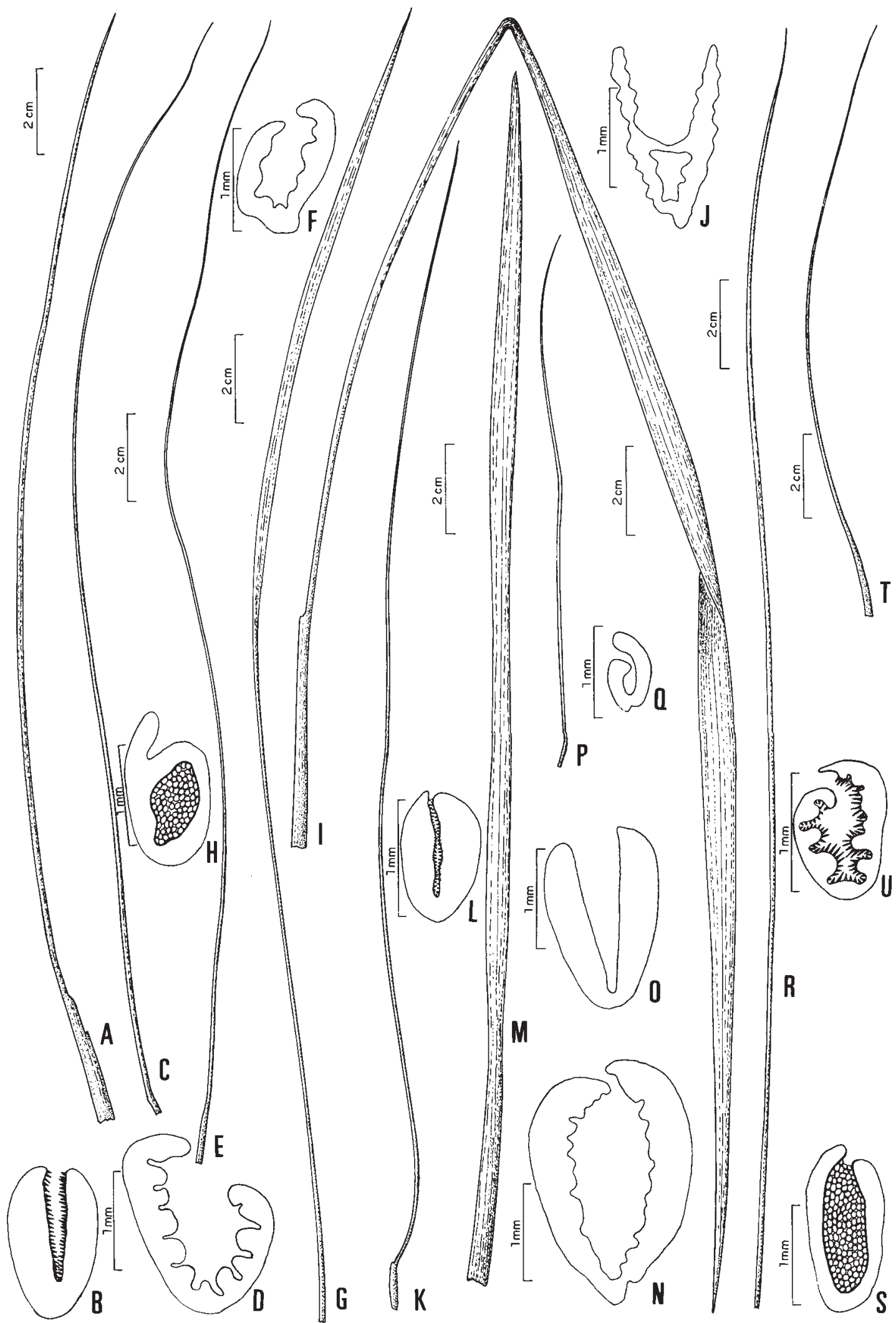

Figura 1. Lâminas foliares e esquemas de cortes transversais. A-B. P. filifolium; C-D. P. cromyorrhizon; E-F. P. approximatum; G-H. P. dedeccae; I-J. P. ionanthum; K-O. P. ellipticum; P-Q. P. crispulum; R-S. P. lineare; T-U. P. pallens (A-B - Valls 11106; C-D - Valls et al. 12813; E-F - Valls 11597; G-H - Valls 11366; I-J - Valls 4795; K-L - Valls 11115; M-N - Valls 9284; O - Valls 11598; P-Q - Macedo 4432; R-S - Oliveira 278; T-U - Valls 13656). 

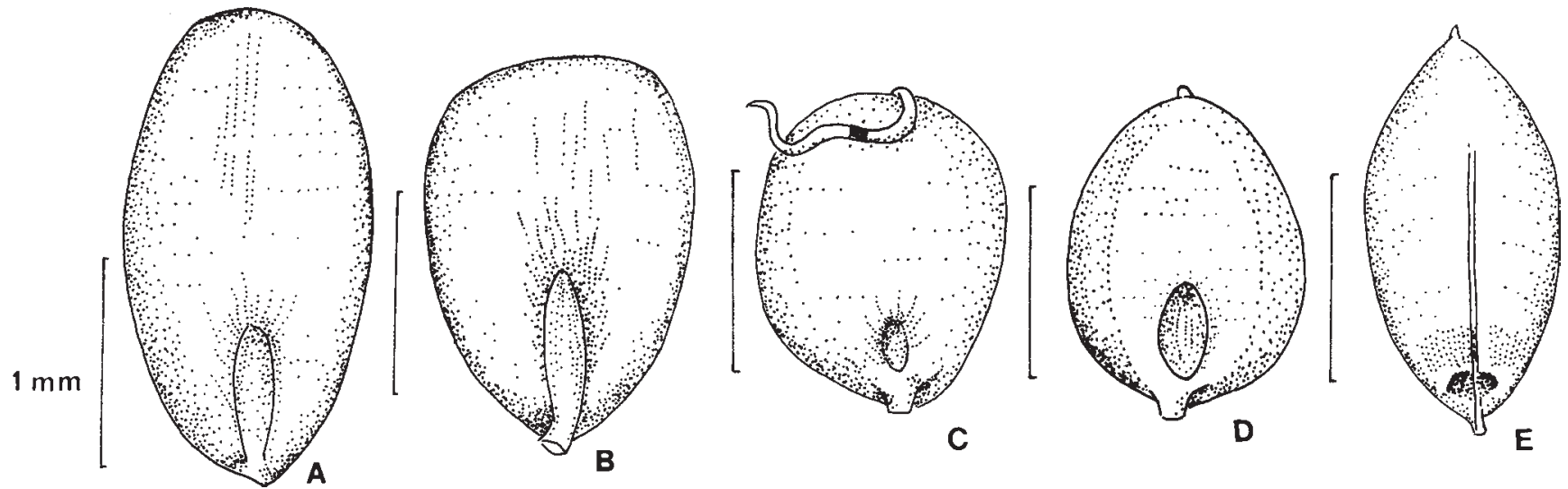

Figura 2. Cariopses, mostrando hilo. A. P. cromyorrhizon; B. P. ionanthum; C. Paspalum maculosum; D. P. ramboi; E. Mesosetum pappophorum (A - Valls 12395; B - Valls 12373; C - Valls 10714; D - Valls 4118; E - Nunes s.n., CEN 7762).

gêneros Mesosetum Steud. (Filgueiras 1986) (figura 2E), Acroceras Stapf, Homolepis Chase, Streptostachys Desv. e Tatianix Zuloaga \& Soderstrom apresentam hilo linear (Zuloaga \& Soderstrom 1985).

Quase todas as espécies de Paspalum dos grupos Linearia e Notata possuem hilo elíptico, segundo a classificação de Filgueiras (1986). O hilo de P. pallens é sub-linear (figura $10 \mathrm{H}$ ). Por outro lado, o hilo de P. plicatulum Michx. e de P. rojasii Hack. é referido como "alongado" por Sendulsky (1965). O hilo dessas duas espécies é semelhante ao de P. pallens (figura 10H). Todavia, Sendulsky (1965) não ressalta este caráter como novo para o gênero, o que aqui é enfatizado. Acentua-se a necessidade de melhor avaliação deste caráter.

Diversas espécies de Paspalum são alopoliplóides, cujos formadores provém de grupos distintos (Quarín 1982). Desta forma, a continuidade do uso dos grupos informais, não reflete aspectos filogenéticos, servindo apenas para fundamentar a distinção morfológica entre plantas do gênero.

\section{Paspalum grupo Linearia}

Plantas perenes, cespitosas; bainhas concentradas na base da planta, as superiores alongadas, com lâminas pouco desenvolvidas ou sem estas; lâminas filiformes, convolutas ou subconvolutas a quase planas (P. ellipticum); inflorescência com 2-3(-5) ramos, muito raramente 1 , os terminais conjugados ou subconjugados; ráquis angulosa, sinuosa, estreita. Espiguetas solitárias, elípticas ou elíptico-ovais, com a forma definida pelo antécio superior; gluma superior e lema inferior semelhantes, 3 ou 5(-7) nervados, membranáceos; antécio superior papiloso (exceto em P. approximatum); cariopses geralmente castanhas, hilo elíptico.

Nomes populares: "Capim-cebola" (Smith et al. 1982) em Santa Catarina. No Pantanal, P. lineare é chamado de "fura-bucho" (Pott \& Comastri-Filho 1995) e na Bahia as espécies do grupo são chamadas "capim-do-agreste", "capim-de-burro" e "canafístula".

Encontradas com flores e frutos de novembro a março. O florescimento mais intenso ocorre após a queima da vegetação. A antese é matutina e se inicia entre o meio e o ápice de cada ramo da inflorescência. Em P. pallens as espiguetas apicais dos ramos da inflorescência são as primeiras a abrirem.

Habitat: Ocorrem em campos úmidos. Paspalum pallens adapta-se a locais com níveis altos de inundação temporária, que cobre suas touceiras, deixando expostos somente os colmos floríferos.

Chave para as espécies do gênero Paspalum, grupo Linearia do Brasil

1. Rizomas longos, conspícuos; colmo florífero com afilhamento ao longo dos nós; folhas dispersas ao longo do colmo

1. Rizomas ausentes ou muito curtos, inconspícuos; colmo florífero sem afilhamento ao longo dos nós; folhas concentradas na base da planta

2. Espiguetas com gluma superior papiloso-pilosa nas margens, freqüentemente com tricomas mais curtos no dorso, especialmente na região apical e lema inferior piloso a quase glabro nas margens 4. P. ellipticum 
2. Espiguetas glabras (com tricomas na base em P. lineare)

3. Gluma superior ausente, exceto, quase sempre, na espigueta apical

3. P. dedeccae

3. Gluma superior sempre presente

4. Espiguetas elíptico-ovadas, gibosas; lema inferior com rugas transversais fortemente marcadas 1. $P$. approximatum

4. Espiguetas elípticas a elíptico-lanceoladas, não gibosas; lema inferior sem rugas ou com rugas levemente marcadas

5. Folhas com lígula conspícua, excurrente, não hialina; espiguetas com ápice agudo 5. P. filifolium

5. Folhas com lígula inconspícua, não excurrente ou, quando excurrente, hialina; espiguetas com ápice obtuso

6. Espiguetas com 3,2-5,6 mm de compr., geralmente com tricomas na base; nós geralmente barbados

6. P. lineare

6. Espiguetas com 1,8-2,1 mm compr., sem tricomas na base; nós glabros 2. P. crispulum

1. Paspalum approximatum Döll in Mart., Fl. bras. 2 (2): 82. 1877. Tipo: BRASIL: MINAS GERAIS, Riedel s.n. (lectótipo, designado por Ekman (1911) W; US frag.).

Paspalum angustifolium Nees ex Trin., Gram. pan. p.99. 1826. non $P$. angustifolium LeConte, 1820 (=P. laeve Michx.), nec Nees ipse 1829. Tipo: BRASIL, sem dados, Sellow s.n. (Lectótipo, designado por Chase (1929) BHU, n.v.).

Paspalum neesii var. undulatum Döll in Mart., Fl. bras. 2 (2): 84. 1877. Tipo: nenhum local citado (não localizado).

Paspalum approximatum Döll var. coarctatum Döll in Mart., Fl. bras. 2(2): 82. 1877. Tipo: BRASIL: MINAS GERAIs, Widgren s.n. (SBT, holótipo, n.v.) syn. nov.

Paspalum parinervium Mez in Engler Bot. Jahrb. 56(125):11. 1921. Tipo: BRASIL: Paraná, Dusén 10489 (B, holótipo n.v.; US e K, isótipos) syn. nov. Figuras 1E-F; 3 A-G; 4C.

Plantas cespitosas, 50-60 cm alt., sem rizoma, delicadas. Colmos floríferos sem afilhamento ao longo dos nós, glabros, com 3-4-(5) nós glabros. Prefoliação conduplicada; folhas concentradas na base da planta; bainhas foliares estriadas, carenadas, glabras na base, com ápice geralmente papiloso-piloso, especialmente nas margens e na região ligular; lígula 0,5-1 $\mathrm{mm}$ compr., não excurrente; lâminas 13-30 × 0,05-0,1 cm, filiformes, convolutas, com tricomas papilosos longos e caducos, especialmente na base e região ligular. Inflorescências com 2 ramos. Espiguetas 2,5-3 $\times$ 1,5-2 $\mathrm{mm}$, elíptico-ovais, obtusas, fortemente gibosas, glabras; gluma inferior ausente, ocasionalmente presente; gluma superior 5-nervada, glabra; lema inferior, 3-5-nervado, glabro, com rugas transversais; antécio superior 2,5-3 × 1,5-2 mm, estriado. Cariopse 1,5-1,8 $\times 1-1,3 \mathrm{~mm}$, orbicular-oboval, com hilo elíptico. $2 \mathrm{n}=2 \mathrm{x}=20$.

Distribuição geográfica: Brasil: BA, GO, MT, MG, PR, TO e MA (figura 4C). Renvoize (1984) não cita P. approximatum para a Bahia. Registra-se, também, a primeira coleta no Maranhão.

Material selecionado: BRASIL: BAHIA: Correntina, 1-XI-1994, R.C. Oliveira 276 (CEN). Goiás: Itiquira, 20-IX-1985, J.F.M. Valls et al. 9278 (CEN). MARANHÃO: Balsas, 20-XI-1995, R.C. Oliveira et al. 3674 (CEN). Mato Grosso: Água Boa, $13^{\circ} 41^{\prime} \mathrm{S}, 052^{\circ} 02^{\prime} \mathrm{W}$, 19-VIII-1984, J.F.M. Valls et al. 7790 (CEN). MinAs Gerais: João Pinheiro, 9-II-1988, J.F.M. Valls \& L. Bianchetti 11597 (CEN). ParanÁ: sem local, s.d., P.K. Dusén 15056 (PKDC). Tocantins: Ilha do Bananal, 1937, Fábio 88 (SP).

Paspalum approximatum é caracterizada pelas rugas transversais do lema inferior e pelo aspecto fortemente giboso de suas espiguetas (figura $3 \mathrm{~B}, \mathrm{C}$ ). Este último caráter leva a uma semelhança com P. maculosum, do grupo Notata. As duas espécies são diferenciadas pela ocorrência de manchas castanho-escuras ou violáceas em mosaico em P. maculosum e do lema inferior rugoso em P. approximatum. Renvoize (1988), apesar de incluir $P$. approximatum em sua chave, tratou este nome como sinônimo de $P$. parinervium Mez no corpo de sua publicação. Contudo, tratou de $P$. approximatum sob autoria de "Ekman non Döll". Desta forma, Renvoize (1988) indicou considerar P. approximatum Ekman como distinta da espécie de Döll e, portanto, um homônimo posterior. Aparentemente por esta razão, aceitou o nome $P$. parinervium como o nome correto, apesar de mais recente. 


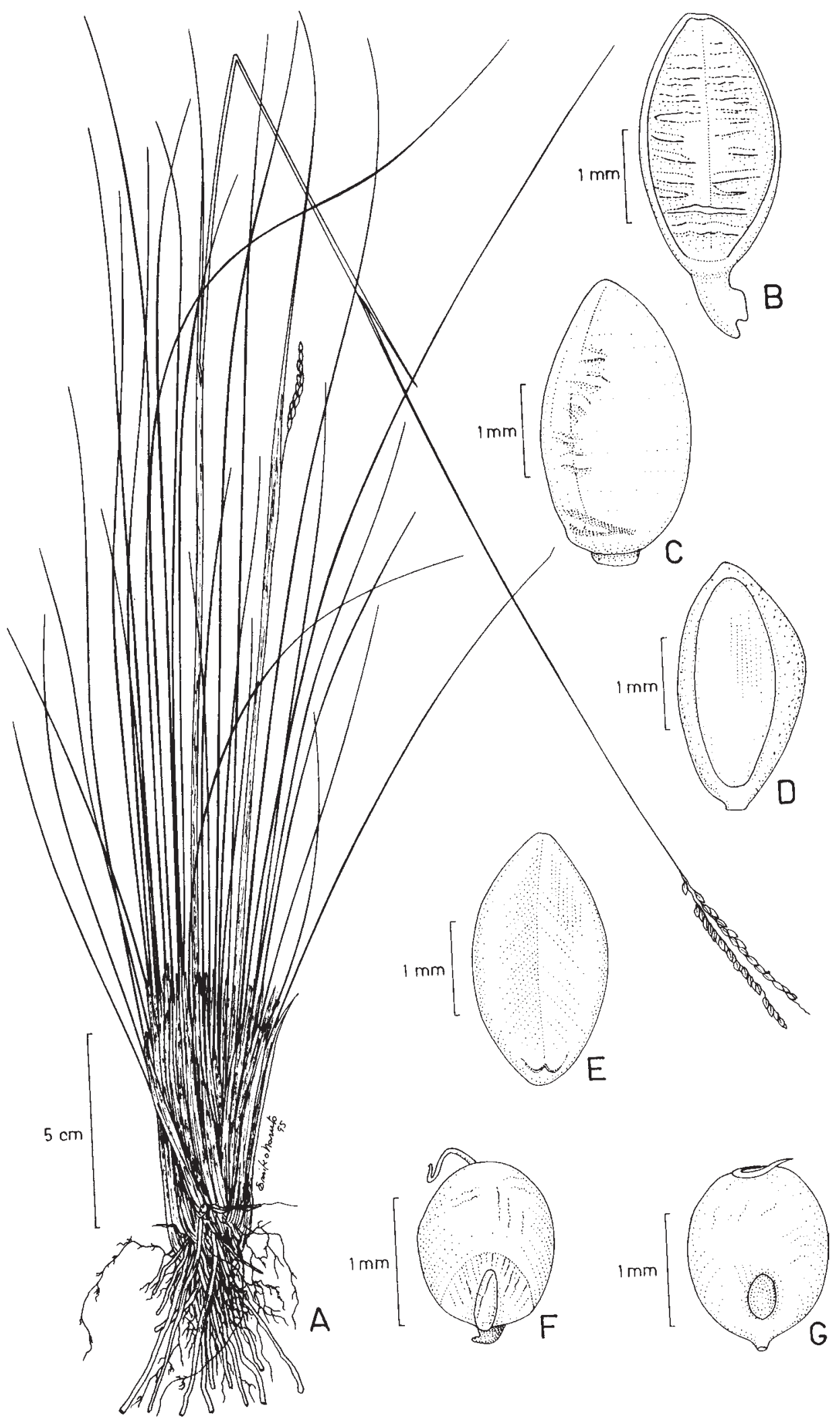

Figura 3. Paspalum approximatum Döll. A. Hábito; B. Espigueta, mostrando lema I; C. Espigueta, mostrando gluma II; D. Antécio fértil, mostrando pálea; E. Antécio fértil, mostrando lema II; F. Cariopse, mostrando região embrionária; G. Cariopse, mostrando hilo. (A-F - Valls 9278; G - Valls 11597). 
2. Paspalum crispulum Swallen, Phytologia 14:365. 1967. Tipo: BRASIL: GoIÁs, Niquelândia, Macêdo, 25-II-1956, A. Macedo 4432 (US, holótipo; SP, BAA, isótipos).

Figuras 1P-Q; 4C; 5A-G.

Plantas cespitosas, $30-50 \mathrm{~cm}$ alt., sem rizomas, delicadas. Colmos floríferos sem afilhamento ao longo dos nós, com esparsos tricomas papilosos no ápice, com 3 nós glabros. Prefoliação convoluta; folhas concentradas na base da planta; bainhas foliares estriadas, carenadas, papiloso-pilosas, com tricomas longos (ca. $3 \mathrm{~mm}$ compr.); lígula ca. $0,4 \mathrm{~mm}$ compr.; às vezes levemente excurrente; lâminas 12-35 × 0,04-0,1 cm, convolutas, filiformes, papiloso-pilosas, especialmente na base, com tricomas caducos, glabras a sub-glabras no ápice. Inflorescências com 2 ramos. Espiguetas 1,8-2,1 × 0,6-1 mm, elípticas, obtusas, não gibosas, glabras; gluma inferior ausente, porém geralmente lembrada por uma pequena cicatriz na base do lema inferior; gluma superior e lema inferior semelhantes, 5-nervados, glabros, sem rugas transversais; antécio superior1,8-2,1 $\times 0,6-1 \mathrm{~mm}$, papiloso. Cariopse $1,7 \times 0,7 \mathrm{~mm}$, elípticas, com hilo elíptico. Dados citogenéticos não disponíveis.

Distribuição geográfica: Paspalum crispulum parece ser endêmica dos arredores de Niquelândia, GO (figura 4C). A região mostra vários endemismos em Paspalum e outros gêneros, incluindo as duas únicas espécies aristadas conhecidas (Davidse \& Filgueiras 1993 e Filgueiras \& Davidse 1994) em Paspalum.

Material selecionado: BRASIL: GoIÁs: Macedo, 14ำ18' S, 48³2' W, 25-VIII-1994, T.S. Filgueiras \& F.C.A. Oliveira 2976 (IBGE).

3. Paspalum dedeccae Quarín, Bonplandia 14 (3):206. 1975. Tipo: ARGENTINA: Corrientes, Santo Tomé, 29 Km E de Ruta Nac. n. 12, camino a Colonia Garabí, 3-XII-1970, Krapovickas et al. 16974 (CTES, holótipo; BAA, BA, MFVA, US, isótipos).

Paspalum neesii var. monachyrium Döll in Mart., F1. bras. 2(3):83. 1877. Tipo: BRASIL: MinAs GERAIS, Caldas, 1854, Lindberg 528 (BRLU, holótipo).

Paspalum doellii Chase ex Filgueiras, Atas Soc. Bot. Brasil, Secç. Rio de Janeiro 1(4):13-18. 1982. Tipo: BRASIL: Distrito Federal, Taguatinga, 9-VIII-1981, T.S. Filgueiras \& B.A.S. Pereira 904 (IBGE, holótipo; SP, isótipo) syn. nov.

Figuras 1G-H; 4D; 6A-G.

Plantas cespitosas, 0,35-1 $\mathrm{m}$ alt., sem rizomas, com touceiras densas. Colmos floríferos sem afilhamento ao longo dos nós, glabros, com 3 nós glabros ou barbados. Prefoliação convoluta; folhas concentradas na base da planta; bainhas foliares estriadas, carenadas, glabras, ocasionalmente com tricomas na margem superior; lígula $0,5-1,3 \mathrm{~mm}$ compr., não excurrente; lâminas $23-52 \times 0,05-1,5 \mathrm{~cm}$ na porção basal, $0,5-1 \mathrm{~cm}$ larg. na porção distal, estreitadas na metade basal e aplanadas na metade distal, lanceoladas, raro totalmente filiformes, densamente papiloso-pilosas, com tricomas caducos. Inflorescência com 2-3(-5) ramos. Espiguetas 3,4-5,1 × 1,7-2,2 $\mathrm{mm}$, elípticas a ovado-elípticas, obtusas, não gibosas, glabras, freqüentemente com tricomas na base; glumas inferior e superior ausentes, freqüentemente a gluma superior está presente na espigueta apical do ramo da inflorescência; lema inferior 5-nervado, glabro, sem rugas transversais; antécio superior 3,4-5,1 $\times 1,7-2,2 \mathrm{~mm}$, fortemente papiloso. Cariopse 2,2-2,5 $\times 0,8-2,3 \mathrm{~mm}$, elíptica, com hilo elíptico. $2 \mathrm{n}=2 \mathrm{x}=20$ (Honfi et al. 1990, Pozzobon et al. 2000) e $2 \mathrm{n}=4 \mathrm{x}=40$ (Quarín \& Burson 1991, Pozzobon et al. 2000).

Distribuição geográfica: Segundo Quarín (1975) e dados deste trabalho, esta espécie ocorre, no Brasil, no DF, GO, MS, MG, PR e SP, na Argentina e no Paraguai (figura 4D).

Material selecionado: BRASIL: DISTRITO FEDERAL: Brasília, 2-IX-1993, G.P. Silva 1803 (CEN). GoiÁs: Teresina de Goiás, 13⒌ $58^{\prime} \mathrm{S}, 047^{\circ} 29^{\prime} \mathrm{W}, 8$-XII-1993, J.F.M. Valls et al. 13444 (CEN). Mato Grosso do Sul: Sidrolândia, 18-I-1988, J.F.M. Valls et al. 11796 (CEN). Minas Gerais: Caldas, 3-11-1845, Widgren s.n. (K, R 16616). PARAnÁ: Castro, $1,8 \mathrm{~km}$ a sudeste de Tronco, ao longo da rodovia de Ponta Grossa a Jaguariaíva, 14-XII-1987, J.F.M. Valls et al. 11240 (CEN); Guarapuava, $24,3 \mathrm{~km}$ a oeste do acesso a Guarapuava ao longo da BR-277, 29-XI-1987, J.F.M. Valls 11366 (CEN). SÃo Paulo: Mogi-Guaçu, 30-XII-1983, $M$. Kuhlmann 4254 (SP, US). ARGENTINA: Misiones, X-1977, A.L. Cabrera et al. 28755 (SI). PARAGUAI: Amambay, IX-1921, T. Rojas 3993 (BAA).

Paspalum dedeccae é caracterizada pela ausência da gluma superior (exceto na espigueta do ápice do ramo florífero). Quarín (1975), relaciona $P$. dedeccae a P. equitans, baseado em caracteres vegetativos. Em P. equitans, as bainhas foliares são aplanadas, as lâminas conduplicadas, a inflorescência multiramosa e a espigueta mostra a gluma superior. Quarín (1975) ressalta a ocorrência da gluma superior em $P$. dedeccae em algumas espiguetas, embora de forma rudimentar. Esta situação não foi observada no presente trabalho, mas a provável ocorrência de sexualidade em parte das 

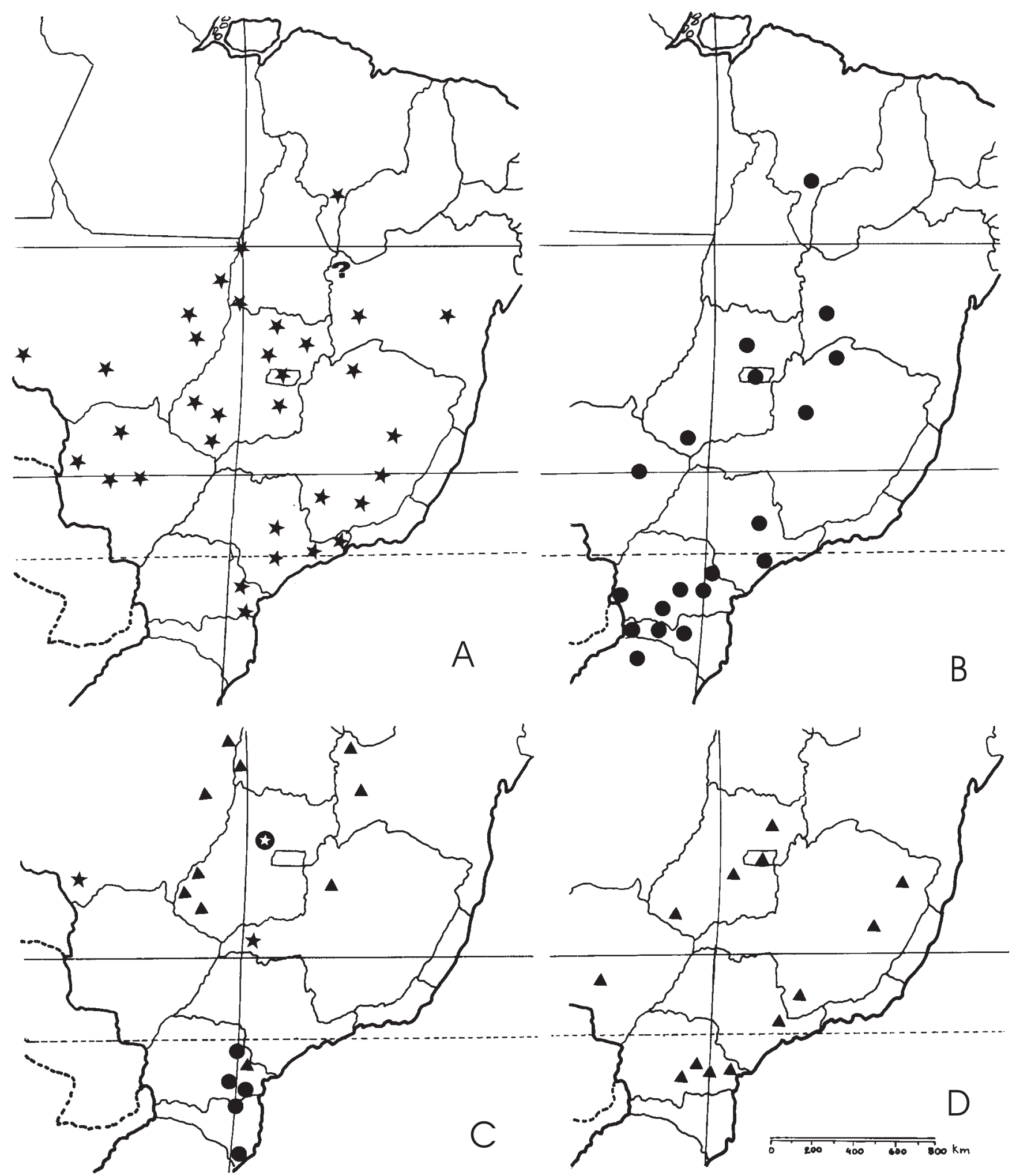

Figura 4. Distribuição geográfica comprovada de espécies brasileiras de Paspalum, grupo Linearia, no Brasil. A. P. lineare $(\star)$; B. P. ellipticum $(\bullet)$; C. P. approximatum $(\mathbf{\Delta})$; P. crispulum $(\bullet)$; P. filifolium $(\bullet)$; P. pallens $(\star)$; D. P. dedeccae $(\mathbf{\Delta})$. 


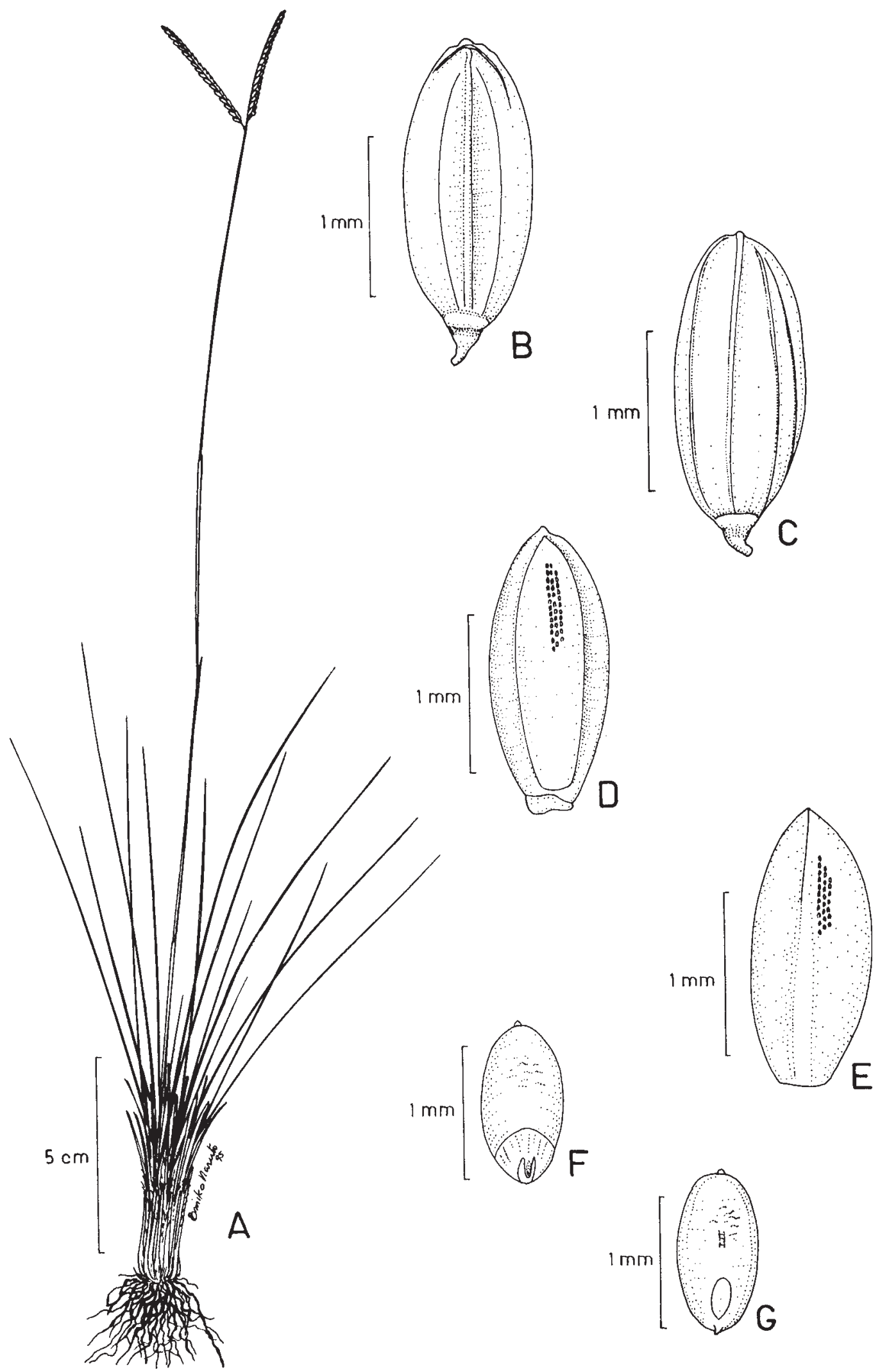

Figura 5. Paspalum crispulum Swallen. A. Hábito; B. Espigueta, mostrando lema I; C. Espigueta, mostrando gluma II; D. Antécio fértil, lado da pálea; E. Antécio fértil, mostrando lema II; F. Cariopse, mostrando região embrionária; G. Cariopse, mostrando hilo (Macedo 4432). 


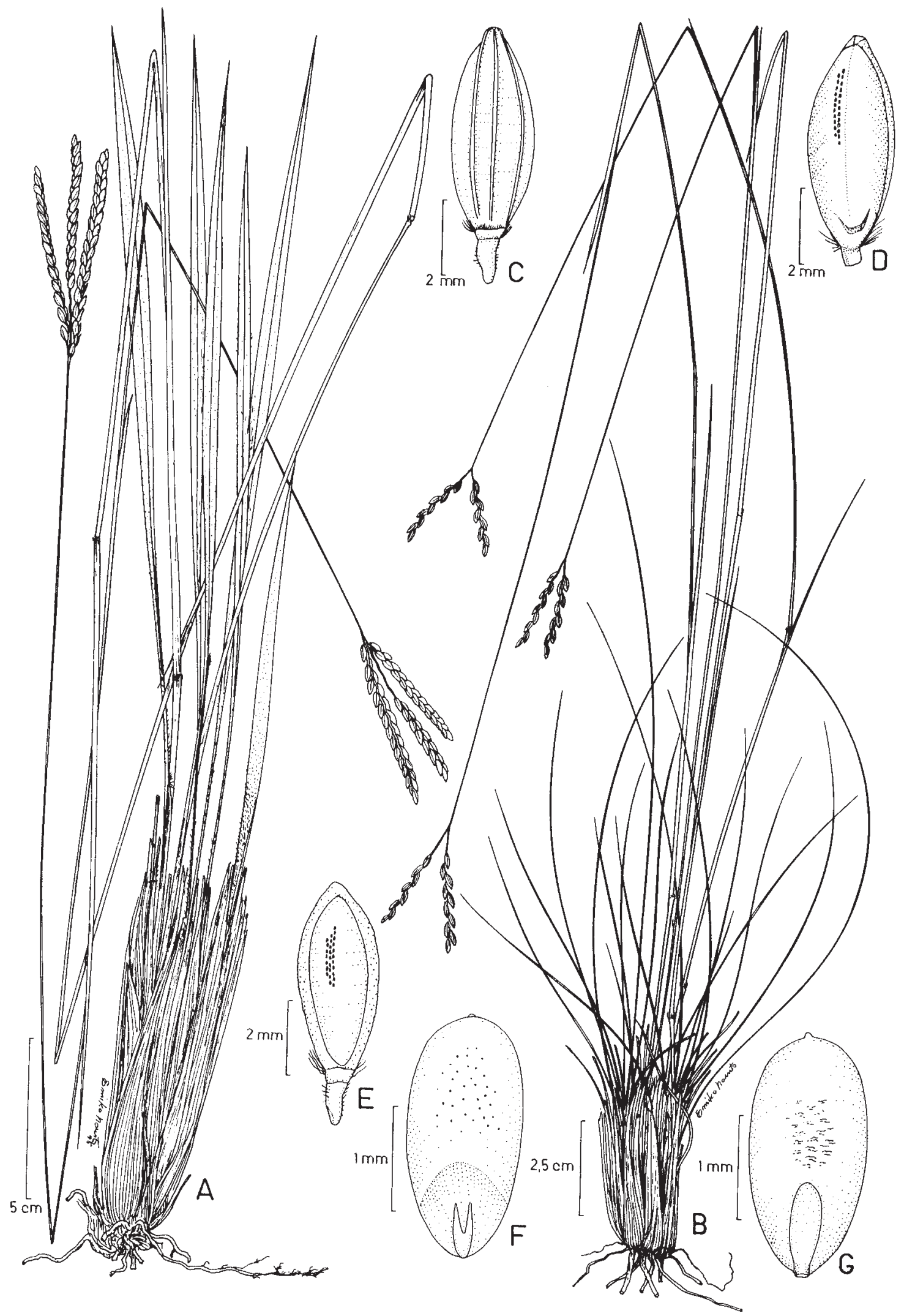

Figura 6. Paspalum dedeccae Quarín. A-B. Hábito, mostrando extremos de variação morfológica; C. Espigueta, mostrando lema I; D. Espigueta, mostrando lema II, evidenciando ausência de gluma II; E. Antécio fértil, mostrando pálea; F. Cariopse, mostrando região embrionária; G. Cariopse, mostrando hilo. (A - Valls 11240; B - Valls 13444; C-G - Valls 11366). 
populações desta espécie, que possui indivíduos diplóides, justificaria ampla variação morfológica. Dedecca (1954) publicou o nome $P$. doellii, atribuindoo a Chase, sem descrição. Segundo Quarín (1975), o nome atribuído por Dedecca não foi validamente publicado, tampouco em Türpe (1966), que também o cita. Quarín (1975), publicou validamente o nome do taxon em questão como $P$. dedeccae.

4. Paspalum ellipticum Döll in Mart., Fl. bras. 2(2):71. 1877. Tipo: BRASIL: São Paulo, Mogi, s.d., Riedel 1650 pro parte (FB, holótipo).

Paspalum ciliocinctum Mez in Engler Bot. Jahrb. 56(125):10. 1921. Tipo: BRASIL: PARANÁ, Jaguariaíva, s.d., Dusén 13273 (B, holótipo; SI, isótipo). syn. nov.

Paspalum proximum Mez, Repert. Spec. Nov. Regni Veg. 15:66. 1919. Tipo: PARAguar: Vila Rica, s.d., Balansa 69 (G-DC, lectótipo designado por Chase \& Niles (1963); US, isolectótipo, frag.).

Figuras 1K-O; 4B; 7A-H.

Plantas cespitosas, 30-160 cm alt., sem rizomas, com touceiras delicadas ou densas. Colmos floríferos sem afilhamento ao longo dos nós, glabros, com 2-5 nós glabros a barbados. Prefoliação conduplicada; folhas concentradas na base da planta; bainhas foliares estriadas, carenadas, glabras ou papiloso-pilosas, principalmente na porção apical, base geralmente velutina; lígula $0,2-1,8 \mathrm{~mm}$ compr., não excurrente; lâminas 21-47 × 0,2-1,5 $\mathrm{mm}$, convolutas ou subconvoluto-subuladas até quase planas, filiformes ou lanceoladas, glabras a glabrescentes, com tricomas papilosos especialmente nas margens. Inflorescências com 2-3(-5) ramos. Espiguetas 3,9-5 × 1,8-2,8 mm, elípticas, obtusas, não gibosas, pilosas; gluma inferior ausente; gluma superior 3,5-5,5 × 1,4-1,9 mm, 3-5-nervada, margem papiloso-pilosa, freqüentemente com tricomas mais curtos no dorso, especialmente na região apical; lema inferior 3-5-nervado, piloso a quase glabro nas margens, glabro no dorso, menos piloso que a gluma, sem rugas transversais; antécio superior 3,3-5 $\times 1,4-2 \mathrm{~mm}$, papiloso. Cariopse com 1,5-1,9 $\times 1-1,4 \mathrm{~mm}$, elíptico-oval, hilo elíptico. $2 \mathrm{n}=4 \mathrm{x}$ $=80$ (Fernandes et al. 1974).

Distribuição geográfica: Segundo Barreto (1957, 1974), esta espécie é rara, encontrando-se esporadicamente em campos baixos do Brasil meridional e, provavelmente, no Paraguai e Uruguai. Angely (1970) e Türpe (1966) citam a espécie como ocorrendo, além do Brasil, no Paraguai, Uruguai e norte argentino, embora não citem o material analisado.
Parodi (1937), Rosengurtt et al. (1970) e Izaguirre-deArtucio \& Garcia (1990) não citam a ocorrência da espécie no Uruguai. Paspalum ellipticum ocorre na Argentina e no Brasil no DF, GO, MS, MG, PR, RS, $\mathrm{SC}$ e SP (figura 4B). Esta é a primeira citação para os estados da Bahia e Maranhão.

Material selecionado: BRASIL: BAHIA: Correntina, 1-XI-1994, R.C. Oliveira 275 (CEN); idem, R.C. Oliveira 277 (CEN). Distrito Federal: Brasília, 14-XII-1986, R.C. Mendonça \& D. Alvarenga 761 (CEN, IBGE, SPF). GoIÁs: Itiquira, 20-X-1985, J.F.M. Valls et al. 9284 (CEN). MARANHÃO: Balsas, 21-III-1997, R.C. Oliveira et al. 366 (CEN). Mato Grosso do Sul: 2044' S, 5337' W, 23-II-1981, J. G. Guimarães 1358 (RB). Minas Gerais: Formoso, $15^{\circ} 08^{\prime} \mathrm{S}, 45^{\circ} 46^{\prime} \mathrm{W}$, 5-XI-1989, T.S. Filgueiras 1911 (IBGE). PARANÁ: Balsa Nova, $3,4 \mathrm{~km}$ a leste do trevo para Irati e Ponta Grossa ao longo da BR-376, 21-XI-1987, J.F.M. Valls et al. 11115 (CEN); 2526' S, 4946' W, 1 km a leste do Rio das Pombas ao longo da BR-376 entre Curitiba e Ponta Grossa, 24-XI-1987, J.F.M. Valls et al. 11170 (CEN); $25^{\circ} 25^{\prime}$ S, 49 $46^{\prime}$ 'W, $2,3 \mathrm{~km}$ ao noroeste do rio das Pombas ao longo da BR-376, 24-XI-1987, J.F.M. Valls et al. 11191 (CEN); Palmeira, 25'21' S, 04947' W, 24-XI-1987, J.F.M. Valls et al. 11219 (CEN). Rio Grande do Sul: Cruz Alta, 5-XII-1986, J.F.M. Valls et al. 10697 (CEN). SANTA Catarina: Abelardo Luz, ca. 263' S, 52²0' W, 15-XI-1964, L.B. Smith \& R.M. Klein 13319 (R, US). São PaUlo: Itirapina, 21-I-1951, G.A. Black 51-10994 (US). ARGENTINA: CoRRIENTES, 14-XI-1974, A. Schinini \& R. Carnevali 10521 (BAA).

Paspalum ellipticum é diferenciada pela ocorrência de tricomas nas espiguetas. Nas exsicatas Valls 11170, Valls 11183 e Valls 11191, observaram-se algumas espiguetas com gluma superior rígida, papilosa, semelhante ao lema inferior em textura. Barreto (1974) considera $P$. proximum sinônimo de $P$. ellipticum. No entanto, Quarín (1975) afirma que são distintas. Segundo este autor, $P$. ellipticum possui lâminas "subconvoluto-subuladas" (figura 1K-L). Por outro lado, P. proximum apresenta lâminas convoluto-filiformes. Chase (dados não publicados) também separa estas duas espécies com base na lâmina foliar. Concluímos pela adoção de uma única espécie biológica, com variação morfológica gradual, desde o morfotipo de $P$. proximum (com folhas muito delicadas, inflorescências e espiguetas menores), passando pelo morfotipo correspondente à ilustração de $P$. ellipticum na Flora Brasiliensis, até um morfotipo "gigante", representado por Valls et al. 9284 (CEN) (figura 7A, B). Paspalum ellipticum possui bom valor forrageiro (Barreto 1957, 1975). 


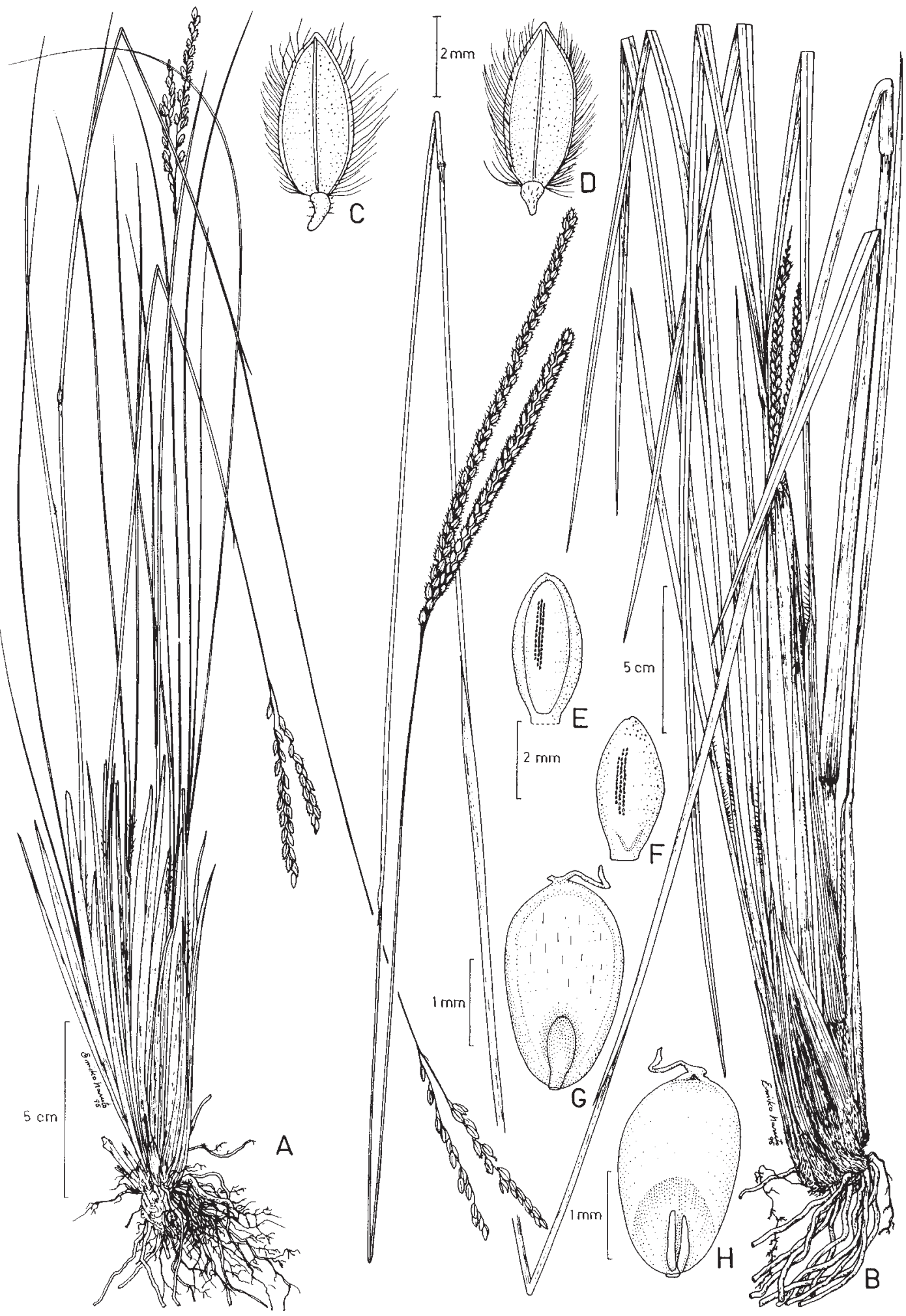

Figura 7. Paspalum ellipticum Döll. A-B. Hábito, mostrando o extremo morfológico descrito sob P. proximum e a forma "gigante" de P. ellipticum, como extremos de variação morfológica na espécie; C. Espigueta, mostrando lema I; D. Espigueta, mostrando gluma II; E. Antécio fértil, mostrando pálea; F. Antécio fértil, mostrando lema II; G. Cariopse, mostrando hilo; H. Cariopse, mostrando região embrionária. (A - Valls 1115; B - Valls 9284; C-F - Valls 10677; G-H - Valls 11219). 
5. Paspalum filifolium Nees ex Steud., Syn. pl. glum. 1:22. 1854 [non P. filifolium Raddi ex Kunth, Enum. pl. 1:582. 1833. (=Axonopus fissifolius Raddi)]. Tipo: BRASIL: São PaUlo, s.d., Sellow s.n. (B, holótipo; K, isótipo).

Figuras 1A, B; 4C; 8A-I.

Plantas cespitosas, 20-100 cm alt., sem rizomas, extremamente delicadas ou robustas. Colmos floríferos sem afilhamento ao longo dos nós, glabros, com 3-4 nós glabros. Prefoliação conduplicada; folhas concentradas na base da planta; bainhas foliares estriadas, exceto nas margens, fortemente carenadas, glabras; lígula 0,8-3,9 mm compr., excurrente; lâminas 6-62 $\times 0,01-0,1 \mathrm{~cm}$, convolutas, filiformes, glabras ou com tricomas papilosos longos e esparsos, caducos, especialmente nas margens e base. Inflorescências com 2-3 ramos de 2,7-10,5 cm compr. Espiguetas 2,9-5,1× 1,2-2,2 mm, fortemente elípticas ou elíptico-lanceoladas, obtusas, não gibosas, glabras; gluma inferior eventualmente presente; gluma superior e lema inferior 3-5 nervados, glabros, sem rugas transversais; antécio superior 2,8-5 × 1,3-2 mm, papiloso. Cariopse 0,8-2,7 $\times 0,8-1,3 \mathrm{~mm}$, obovada a lanceolada, com hilo elíptico. $2 \mathrm{n}=2 \mathrm{x}=20$ (Pozzobon et al. 2000).

Distribuição geográfica: Provavelmente endêmica do Paraná e Santa Catarina, entre $25^{\circ}-30^{\circ} \mathrm{S}$ e $49^{\circ}-51^{\circ}$ $\mathrm{W}$, onde ocupa regiões de grandes altitudes (figura 4C). A localização do tipo no Estado de São Paulo pode ser função de sua ocorrência no Paraná, que, até 1853 , pertenceu a São Paulo. A Lei número 704 de 19-10-1853 desmembrou o Paraná de São Paulo

Material selecionado: BRASIL: PARANÁ: Balsa Nova, 2527' S, 04940' W, entre o Posto 39 e a Polícia Rodoviária ao longo da BR-376, 21-XI-1987, J.F.M. Valls et al. 11106 (CEN); idem, $1 \mathrm{~km}$ a leste do Rio das Pombas ao longo da BR-376 entre Curitiba e Ponta Grossa, 24-XI-1987, J.F.M. Valls et al. 11186 (CEN). SANTA CATARINA: Bom Jardim da Serra, 28 ${ }^{\circ} 23^{\prime}$ S, 49³4' W, 5-XII-1988, J.F.M. Valls et al. 11986 (CEN).

Paspalum filifolium é diferenciada pela lígula excurrente e muito desenvolvida (figura 8C). Döll (1877) e Smith et al. (1982), atentam para a lígula "muitas vezes incisa ou bífida" de P. filifolium. Esta espécie, embora pouco representada em herbários, possui grande variação morfológica. Apresenta plantas desde extremamente delicadas até robustas (figura $8 \mathrm{~A}, \mathrm{~B})$.

6. Paspalum lineare Trin., Gram. pan. p.99. 1826. [non P. lineare Swartz ex Steud., Nom. Bot. ed. 2. 2:272.
1841. (= P. swartzianum Fluegge $=P$. filiforme $\mathrm{Sw}$.), nec $P$. lineare Fournier, Mex. P1. 2:12. 1886 (=P. caespitosum Fluegge)]. Tipo: BRASIL: MINAS Gerais, Serra da Lapa, s.d., Langsdorff s.n. (LE, holótipo).

Paspalum neesii Kunth, Rév. gram. 1:25. 1829. (Baseado em Paspalum angustifolium Nees, Agrost. bras. 64. 1829. non $P$. angustifolium LeConte, 1820). Tipo: Fazenda do "Buraxudo", 7-XII-1818, Sellow s.n. (B, lectotipo designado por Chase, 1929).

Panicum furcellatum S. Moore, Trans. Linn. Soc. London. Ser. 2. 4:505. pl. 34. 14-22. 1895. Tipo: BRASIL: Mato Grosso, Santa Cruz, s.d., Moore 763 (BM, holótipo, n.v.).

Paspalum tropicum Döll in Mart., Fl. bras. 2 (2): 83. 1877. Tipo: BRASil: Pernambuco ou Piaui, rio Preto, s.d., Gardner 2975 (G-DC, holótipo, n.v.; US, $\mathrm{K}$, isótipos).

Figuras 1R, S; 4A; 9A-G.

Plantas cespitosas, $30-110 \mathrm{~cm}$ alt., sem rizomas, com touceiras densas. Colmos floríferos glabros, sem afilhamento ao longo dos nós, com 2-3(-4) nós, glabros ou barbados. Prefoliação convoluta. Folhas concentradas na base da planta; bainhas foliares estriadas, carenadas, pubescentes a subglabras, com freqüência pilosas no ápice, especialmente na região ligular, com tricomas papilosos, base velutina; lígula não excurrente, 0,1-1,2 mm compr.; lâminas 12-50 × 0,07-0,17 cm, conduplicadas, filiformes, com pubescência caduca diminuindo de forma gradual para o ápice, em geral com tricomas papilosos, raro glabras. Inflorescência com 2-3(-4) ramos. Espiguetas 3,2-5,6 $\times$ 1,2-2,7 mm, elípticas, obtusas, não gibosas, em geral com tricomas na base; gluma inferior ausente, raramente presente; gluma superior (4-)5-nervada, glabra, porém, em geral, levemente ciliada na base, quando imatura; lema inferior 5(-7) nervado, glabro, sem rugas transversais; antécio superior 3-5 × 1-2 mm, papiloso. Cariopse 2-2,8 x 1-1,3 mm, elíptica, com hilo elíptico. $2 \mathrm{n}=8 \mathrm{x}=80$ (Norrmann et al. 1994) $2 \mathrm{n}=2 \mathrm{x}=20$ e $2 \mathrm{n}$ $=2 \mathrm{x}=40$.

Distribuição geográfica: Segundo Hitchcock (1936) e Chase (1929), esta espécie ocorre da Costa Rica até Argentina, Cuba e Hispaniola. No Brasil nos estados da BA, DF, GO, MT, MS, MG, TO e SP (figura 4A).

Segundo Chase (dados não publicados), o tipo de $P$. tropicum (sinônimo de $P$. lineare), não tem localização precisa. Pernambuco possuía uma área geográfica maior que a atual, estendendo-se por grande 


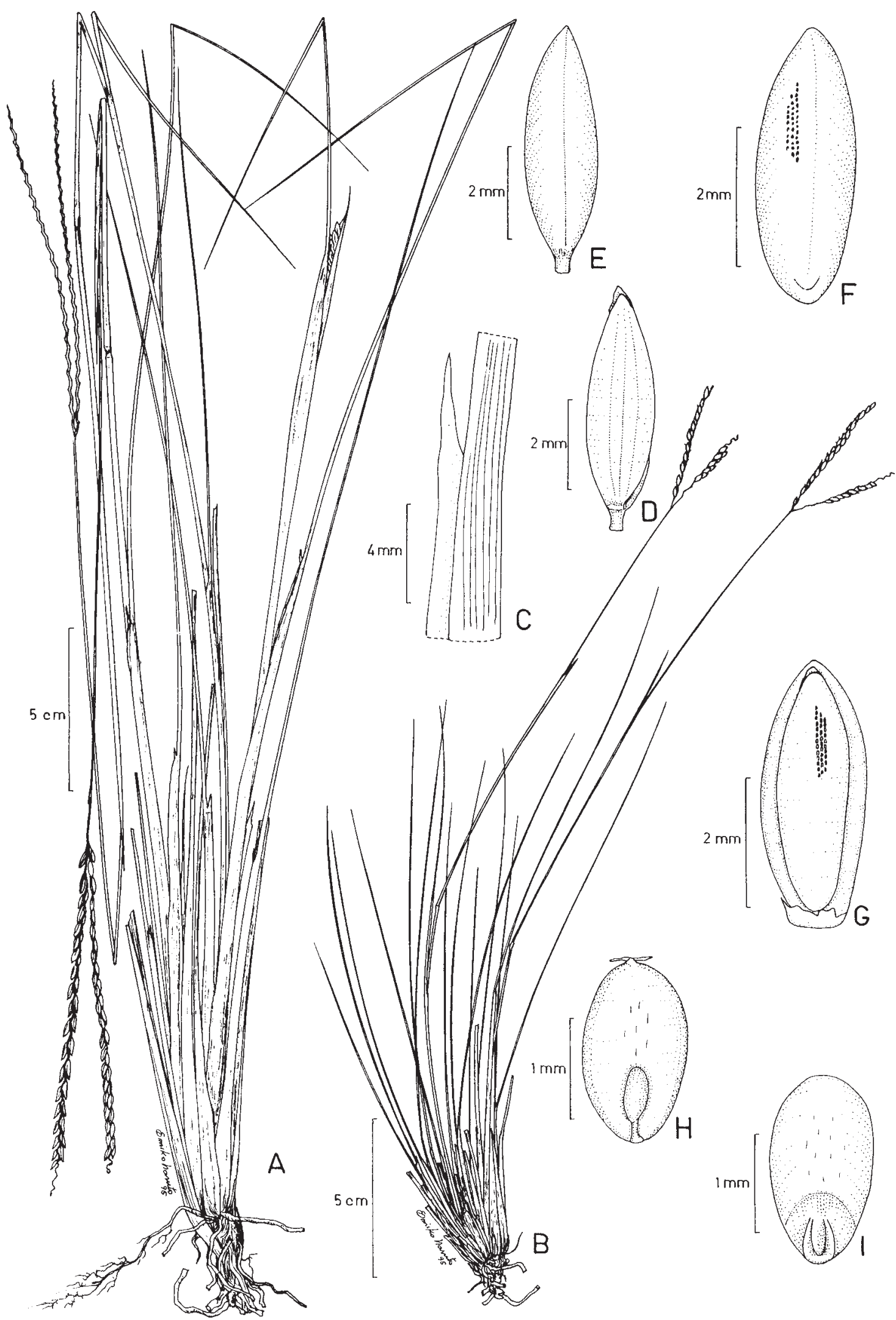

Figura 8. Paspalum filifolium Nees. A-B. Hábito, mostrando extremos de variação morfológica; C. Lígula; D. Espigueta, mostrando lema I; E. Espigueta, mostrando gluma II; F. Antécio fértil, mostrando lema II; G. Antécio fértil, mostrando pálea; H. Cariopse, mostrando o hilo; I. Cariopse, mostrando a região embrionária. (A, D-G - Valls 11186; B - Valls 11986; H-I - Valls 11106). 


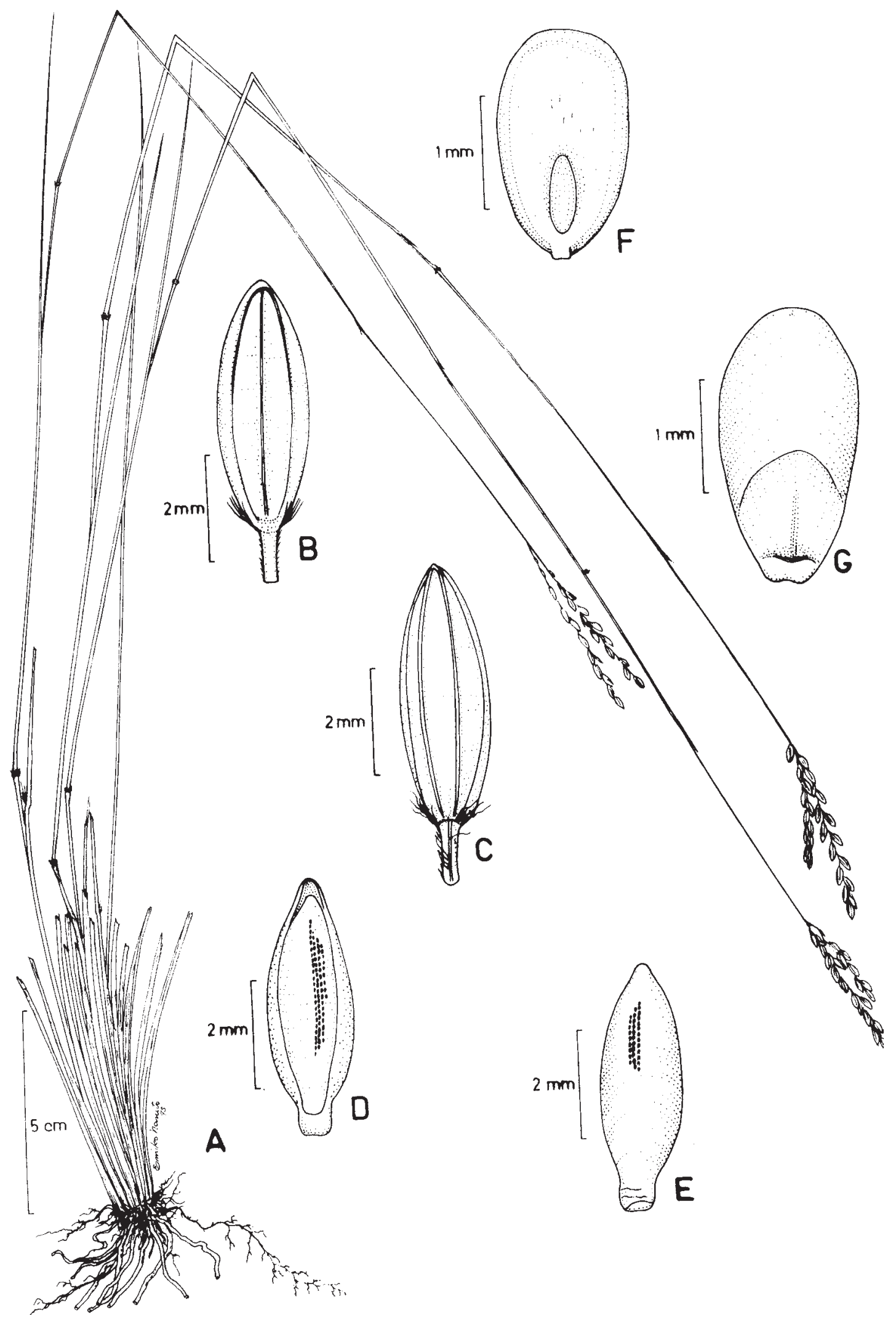

Figura 9. Paspalum lineare Trin. A. Hábito; B. Espigueta, mostrando lema I; C. Espigueta, lado da gluma II; D. Antécio fértil, mostrando pálea; E. Antécio fértil, mostrando lema II; F. Cariopse, mostrando hilo; G. Cariopse, mostrando a região embrionária. (A - Valls 13428; B-E - Valls 9478; F-G - Valls 10480). 
área pertencente, hoje, à Bahia, onde está o rio Preto. Portanto, a localização deste espécimen foi situada, na figura $4 \mathrm{~A}$, dentro dos limites deste último estado, sinalizada com uma interrogação.

Material selecionado: BRASIL: BAHIA: Correntina, 1-XI-1994, R.C. Oliveira 278 (CEN). Distrito FedERAL: Planaltina, 28-XI-1988, J.F.M. Valls et al. 11947 (CEN). GoIÁs: Simolândia, $14^{\circ} 28^{\prime}$ S, 046²9' W, pouco ao norte da rodovia Simolândia-Juciara, logo a oeste do córrego Salobro, 9-XI-1993, J.F.M. Valls et al. 13428 (CEN). Mato Grosso: Nossa Senhora do Livramento, 4-XI-1986, J.F.M. Valls et al. 10480 (CEN). MAто Grosso do Sul: Rio Verde, 29-X-1985, J.F.M. Valls et al. 9478 (CEN). Minas Gerais: Formoso, 1508' S, 4546' W, 5-XI-1989, T.S. Filgueiras 1908 (IBGE). PARANÁ: Balsa Nova, 2526’ S, 04946’ W, 24-XI-1987, J.F.M. Valls 11169 (CEN). São Paulo: Botucatu, 22-XI-1968, T. Sendulsky 863 (SP). Tocantins: Ilha do Bananal, ca. 10³0' S, 50³0' W, 21-IX-1980, J.A. Ratter et al. 4480 (UB, UEC). ARGENTINA: MISIONES - SAn José, II-1922, J.F. Molfino 4714 (BAA). BOLÍVIA: SANTA Cruz, $16^{\circ} 08^{\prime} \mathrm{S}$; $62^{\circ} 05^{\prime} \mathrm{W}$, 10-XI-1986, T. Killeen 2218 (MO). COLOMBIA: Comisaría Del Vichada, 23-I-1944, F.J. Hermann 11079 (US). MÉXICO: AgVacate Palenque, 16-19-VII-1939, E. Matuda 3800 (US). PARAGUAI: 1908-1909, K. Fiebrig 4996 (BAA, US); CHACO, Verano 1917, A.C. Muello 4703 (BAA).

Paspalum lineare é freqüentemente caracterizada pelos nós barbados (Trinius 1828, Parodi 1923, Chase 1929, Hitchcock 1936, Renvoize 1988). Porém, no Brasil, a espécie apresenta variação desde nós barbados até glabros. Hitchcock (1936) chama a atenção à pilosidade na base da espigueta de $P$. lineare. Este caráter também apresenta grande variabilidade, já que os tricomas são caducos. Paspalum tropicum é considerado sinônimo de $P$. lineare (Killeen 1990). Chase (dados não publicados), considera $P$. tropicum como sinônimo de $P$. filifolium Nees, embora não formalmente. Ressalta que o tipo de $P$. tropicum difere de P. filifolium pelos "nós apresso-pubescentes, bainhas hirsutas no ápice, lígula obscura, não excurrente, hirsuta na base e racemos menores, longo pilosos na base". Estes caracteres são diagnósticos para a separação das duas espécies, sendo típicos de P. lineare. Döll (1877) diferenciou $P$. tropicum de $P$. filifolium pelas espiguetas e lígula menores, o lema fértil e pálea, escabrosos. Os isotipos de $P$. tropicum analisados no decorrer deste trabalho, são de exemplares de $P$. lineare.

7. Paspalum pallens Swallen, Phytologia 14:365. 1967.
Tipo: BRASIL: Minas Gerais, Ituiutaba, Santa Terezinha, 18-II-1950, A. Macedo 2167 (US, holótipo).

Paspalum fessum Swallen, Phytologia 14:365. 1967. Tipo: BRASIL: Minas GERAIs, Ituiutaba, Praião, 3-IX-1950, A. Macedo 2543 (US, holótipo).

Figuras 1T-U; 4C; 10A-H.

Plantas cespitosas, estoloníferas, 30-105 cm alt., rizomas desenvolvidos, touceiras delicadas. Colmos floríferos glabros, com afilhamento ao longo dos nós, com 3-8 ou mais nós, glabros. Prefoliação convoluta; folhas distribuídas ao longo do colmo; bainhas foliares estriadas, carenadas, glabras, exceto nos estolões, onde as bainhas possuem tricomas longos na base e margem; lígula 5-12 mm compr., não excurrente, em geral com 2 dentes apicais; lâminas 15-35 × 0,8-1,2(-3) mm, convolutas, filiformes, ligeiramente subuladas, glabras ou com tricomas longos marginais na base. Inflorescências com (1-)2 ramos. Espiguetas 2,2-3,5 × 0,8-1,2 mm, elípticas, obtusas, não gibosas, glabras; gluma inferior ausente; gluma superior 5-7(-8) nervada, glabra; lema inferior 5-7 nervado, glabro, sem rugas transversais; antécio superior 2,2-3,5 × 0,8-1,1 mm, papiloso. Cariopse 1,9-2,4 $\times 0,5-0,10 \mathrm{~mm}$, estreitamente obovada, com hilo sub-linear. $2 \mathrm{n}=20$ (Killeen 1990).

Distribuição geográfica: Pouco coletada, sendo conhecida, no Brasil, em Minas Gerais, no município de Ituiutaba e no Mato Grosso. Na Bolívia, foi muito coletada nos arredores de Santa Cruz de la Sierra. Provavelmente, a distribuição desta espécie seja mais ampla do que é demonstrado pelas coletas (figura 4C).

Material selecionado: BRASIL: Material cultivado em casa-de-vegetação da Embrapa-Cenargen, a partir dos acessos J.F.M. Valls et al. 13655 e 13656, ambos de Capinópolis, MG, 17-X-1995, R.C. Oliveira 358 (CEN). Mato Grosso: Santo Antônio do Leverger, 30 IV-1995, J.F.M. Valls et al. 13784 (CEN). MINAS GERAIS: Capinópolis, fazenda Santa Terezinha, ao longo da antiga estrada de acesso pela atual fazenda Moleque, 23-II-1984, J.F.M. Valls \& V.R. Rao 7534 (CEN). BOLÍVIA: SANTA CRUZ, $16^{\circ} 2^{\prime} \mathrm{S}, 62^{\circ} 05^{\prime} \mathrm{W}, 11-\mathrm{I}-1986$, T. Killeen 1590 (MO).

Paspalum pallens é confundida com $P$. filifolium. Estas espécies são diferenciadas pela concentração das folhas na base da planta, ausência de rizomas, falta de afilhamento lateral no colmo e presença de lígula excurrente em P. filifolium (figura 8A-B). Nas exsicatas de $P$. pallens, não se encontra evidência da formação de estolões, exceto em Valls 13784. Entretanto, plantas de $P$. pallens em cultivo (Oliveira 358), coletadas próximo à localidade do tipo, apresentam estolões. 


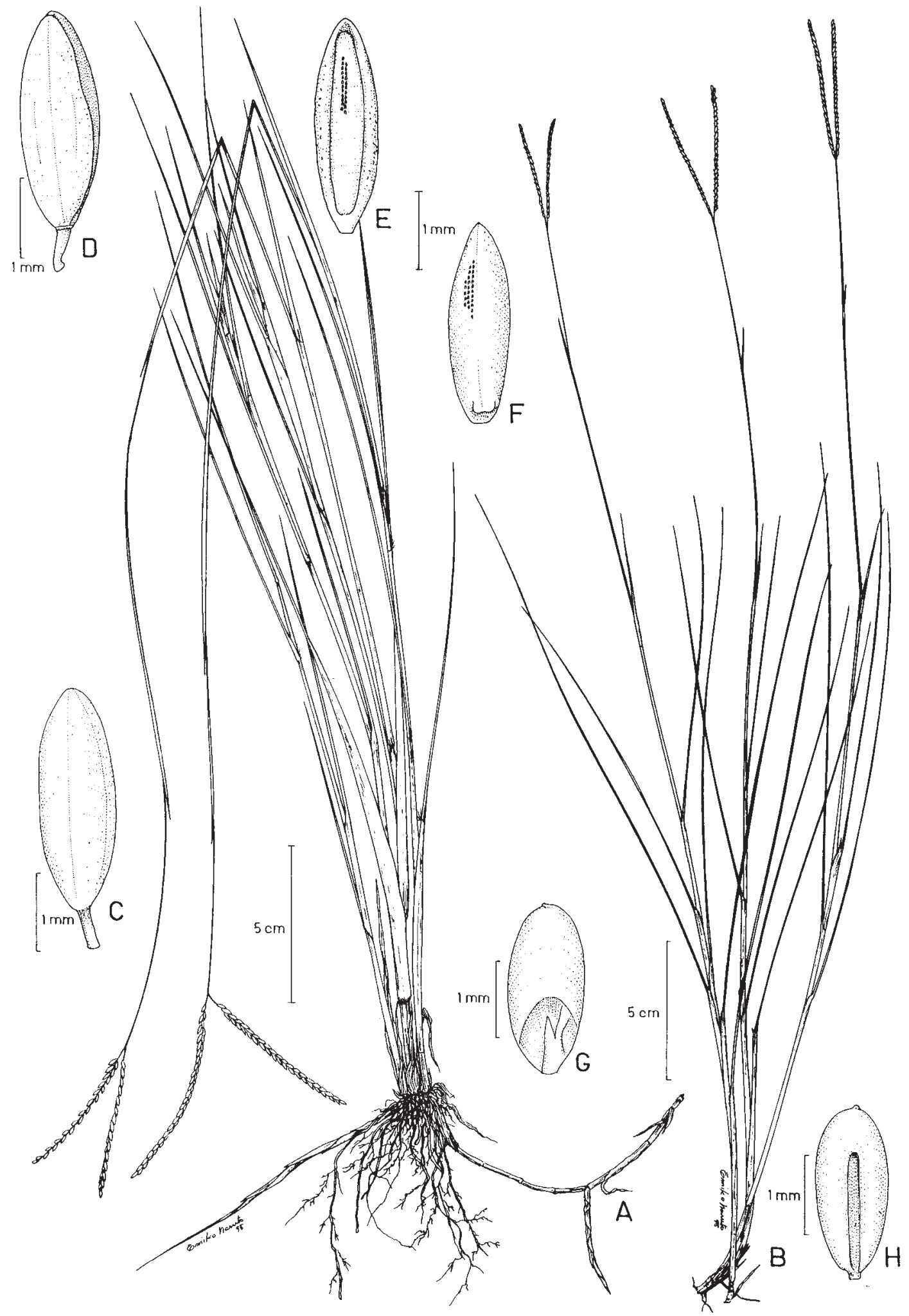

Figura 10. Paspalum pallens Swallen. A-B. Hábito, mostrando a morfologia de P. pallens e P. fessum, respectivamente, segundo o conceito de Swallen (1967); C. Espigueta, mostrando gluma II; D. Espigueta, mostrando lema I; E. Antécio fértil, mostrando pálea; F. Antécio fértil, mostrando lema II; G. Cariopse, mostrando a região embrionária; H. Cariopse, mostrando hilo. (A, G-H - Valls 13656; B - Macedo 2543; C-F - Valls 7534). 
Agradecimentos - À Capes pela Bolsa de mestrado cedida e aos curadores dos herbários consultados.

\section{Referências bibliográficas}

ANGELY, J. 1954. Flora do Paraná: Gramíneas paranaenses. Revista do Instituto Paranaense de Botânica 2:3-13.

ANGELY, J. 1958. Flora do Paraná: Lista de holotypus. Revista do Instituto Paranaense de Botânica 12:3-23.

ANGELY, J. 1970. Flora analítica e fitogeográfica do estado de São Paulo. Revista de Farmácia e Bioquímica da Universidade de São Paulo 8:139-142.

BARRETO, I.L. 1957. Las especies de Paspalum con dos racimos conjugados en Rio Grande del Sur (Brasil). Revista Argentina de Agronomía 23:53-70.

BARRETO, I.L. 1974. O gênero Paspalum (Gramineae) no Rio Grande do Sul. Tese de livre docência, Universidade Federal do Rio Grande do Sul, Porto Alegre.

BARRETO, I.L. \& KAPPEL, A. 1967. Principais espécies de gramíneas e leguminosas das pastagens naturais do Rio Grande do Sul. Boletim Técnico da Secretaria de Agricultura do Rio Grande do Sul 7:281-294.

BURSON, B.L. \& QUARÍN, C.L. 1982. Cytology of Paspalum virgatum and its relationship with $P$. intermedium and P. juergensii. Canadian Journal of Genetic and Cytology 24:219-226.

CANTO-DOROW, T.S., Longhi-Wagner, H.M. \& Valls, J.F.M. 1996. Revisão taxonômica das espécies de Paspalum L. grupo Notata (Poaceae-Paniceae) do Rio Grande do Sul, Brasil. Iheringia 47:3-44.

CHASE, A. 1929. The North American species of Paspalum. Contribution from the United States National Herbarium 28:1-310.

CHASE, A. \& NILES, C.D. 1962. Index to grass species. G.K. Hall, Massachusetts, v.3.

DAVIDSE, G. \& FILGUEIRAS, T.S. 1993. Paspalum longiaristatum (Poaceae: Paniceae), a new serpentine endemic from Goiás, Brazil, and the first awned species in the genus. Novon 3:129-132.

DEDECCA, D.M. 1954. Contribuição para o levantamento agrostológico de município de Campinas. Bragantia $13: 1-21$.

DÖLL, J.C. 1877. Gramineae II. In Flora brasiliensis (C.F.P. Martius \& A.W. Eichler, eds.). F. Fleischer, Monachii, v.2, pars. 2, p.39-119.

EKMAN, E.L. 1911. Neue brasilianische Gräser. Arkiv för Botanik 10:1-43.

FERNANDES, M.I.B. 1974. Cytological and evolutionary relationships in Brazilian forms of Paspalum (Gramineae). Caryologia 27:455-465.

FILGUEIRAS, T.S. 1982. Uma nova espécie de Paspalum L. (Gramineae) do Brasil Central. Atas da Sociedade Botânica do Brasil: secção Rio de Janeiro 1:13-18.

FILGUEIRAS, T.S. 1986. O conceito de fruto em gramíneas e seu uso na taxonomia da família. Pesquisa Agropecuária Brasileira 21:93-100.
FILGUEIRAS, T.S. 1993. Nomenclatural and critical notes on some Brazilian species of Paspalum (Poaceae: Paniceae). Acta Amazonica 23:147-161.

FILGUEIRAS, T.S. \& DAVIDSE, G. 1994. Paspalum biaristatum (Poaceae: Paniceae), a new serpentine endemic from Goiás, Brazil, and the second awned species in the genus. Novon 4:18-22.

HENRARD, J.T. 1941. Notes on the nomenclature of some grasses. Blumea 4:411-480.

HITCHCOCK, A.S. 1936. Manual of the grasses of the West Indies. United States Department of Agriculture (Miscellaneous publication 243), Washington.

HOLMGREN, P.K., HOLMGREN, N.H. \& BARNETT, L.C. (eds.). 1990. Index Herbariorum. Part I: The herbaria of the world. $8^{\text {th }}$ ed. New York Botanical Garden, New York

HONFI, A.I., QUARÍN, C.L. \& VALLS, J.F.M. 1990. Estudios cariológicos en gramineas sudamericanas. Darwiniana 30:87-94.

IZAGUIRRE-DE-ARTUCIO, P. \& GARCÍA, S.G. 1990. Novedades agrostológicas para el Uruguay. In Anais do II Seminário Nacional de Campo Natural. TacuarembóUruguai, p.179-181.

KILLEEN, T.J. 1990. The grasses of Chiquitania, Santa Cruz, Bolivia. Annals of the Missouri Botanical Garden 77:125-201.

NORRMANN, G.A. 1994. Chromosome numbers in Bolivian grasses. Annals of the Missouri Botanical Gardern 81:768-783.

PARODI, L.R. 1923. Nuevas gramíneas para la flora Argentina. Physis 7:56-62.

PARODI, L.R. 1937. Contribución al estudio de las gramíneas del género Paspalum de la flora Uruguaya. Revista del Museo de La Plata 1 (n.s.):211-250.

POTT, A. \& COMASTRI FILHO, J.A. 1995. Pastagens no ecossistema Pantanal: pesquisas para o desenvolvimento sustentável. In Anais do Simpósio sobre Ecossistema de Pastagens e XXXII Reunião Anual da Sociedade Brasileira de Zootecnia (V. Favoretto \& L.R. de A. Rodrigues, eds.). Brasília, p.1-27.

POZZOBON, M.T., VALLS, J.F.M. \& SANTOS, S. 2000. Contagens cromossômicas em espécies brasileiras de Paspalum L. (Gramineae). Acta Botanica Brasilica 14:151-162.

QUARÍN, C.L. 1975. Notas sobre el género Paspalum (Gramineae). Bonplandia 3:195-210.

QUARÍN, C.L. \& HANNA, W.W. 1980. Chromosome behavior, embryo sac development, and fertility of Paspalum modestum, P. boscianum, and P. conspersum. Heredity 71:419-422.

RADFORD, A.E. 1986. Fundamentals of plant systematics. Harper \& Row, New York.

RENVOIZE, S.A. 1984. The grasses of Bahia. Royal Botanical Gardens, Kew. 
RENVOIZE, S.A. 1988. Hatschbach's Paraná grasses. Royal Botanical Gardens, Kew.

ROSENGURTT, B., ARRILAGA-DE-MAFEI, B.R. \& IZAGUIRRE-DE-ARTUCIO, P. 1970. Gramíneas Uruguayas. Universidad de la República, Montevideo.

SENDULSKY, T. 1965. Contribution to the study of fruits and associated structures of grasses from the "cerrados" (Aristida, Chloris, Mesosetum, Sorghastrum, Tristachya, Eragrostis and Paspalum). Acta Biologica Venezuelica 4:421-463.

SMITH, L.B., WASSHAUSEN, D.C. \& KLEIN, R.M. 1982. Gramíneas. In Flora Ilustrada Catarinense (R. Reitz, ed.). Herbário Barbosa Rodrigues, Itajaí, v.3, p.911-1099.

SWALLEN, J.R. 1967. New species of Paspalum. Phytologia $14: 358-360$.
TRINIUS, M.B. 1828. Species graminum. Iconibus et descriptionibus. Imprensis Academiae Imperialis Scientiarum, Reprint 1970. J. Cramer. New York, v.1.

TÜRPE, A.M. 1966. Histotaxonomía de las especies Argentinas del género Paspalum. Lilloa 32:1-272.

VALLS, J.F.M. \& POZZOBON, M.T. 1987. Variação apresentada pelos principais grupos taxonômicos de Paspalum com interesse forrageiro no Brasil. Anais do Encontro Internacional sobre Melhoramento Genético de Paspalum (Y.H. Savidan, P.B. Alcântara, J.F.M. Valls, C. Quarín \& A.R.P. de Almeida, eds.). Instituto de Zootecnia, SAPF-DNAP-IZ, CNPGC-Embrapa, Orstom e Procisur, Nova Odessa, p.15-21. 